\title{
Clinical follow up of patients with premature coronary artery disease (PCAD) implanted with drug-eluting stents
}

\author{
Xiaofeng Zhang ${ }^{1}$, Yong Tang ${ }^{1}$, Genshan $\mathrm{Ma}^{2}$, Zhong Chen ${ }^{2 *}$ \\ ${ }^{1}$ Department of Cardiology, The Affiliated Nanjing Second Hospital of Southeast University, Nanjing, China \\ ${ }^{2}$ Department of Cardiology, The Affiliated Zhongda Hospital and School of Medicine, Southeast University, Nanjing, China \\ Email: "zhongchen7498@hotmail.com
}

Received 20 May 2013; revised 2 June 2013; accepted 15 June 2013

Copyright (C) 2013 Xiaofeng Zhang et al. This is an open access article distributed under the Creative Commons Attribution License, which permits unrestricted use, distribution, and reproduction in any medium, provided the original work is properly cited.

\begin{abstract}
Background: Drug-eluting stents (DESs) are associated with lower restenosis rates. However, minimal data on the follow up results of premature coronary artery disease (PCAD) treated with DESs exist. This study was to evaluate clinical characteristics and oneyear prognosis of PCAD implanted with DESs in a Chinese population. Methods: 282 patients with PCAD, of which 177 implanted with DESs and 105 prescribed medicine alone were enrolled and analyzed. Major adverse cardiovascular events (MACEs) and the use of medications for secondary prevention were collected and analyzed. Results: Compared with those receiving medicine alone, patients implanted with DESs had higher ratios of males than females, they also had acute coronary syndromes, multi-vessel disease, higher values of cardiac troponin I, longer hospital stays, higher aspirin and clopidogrel use (all $P<0.05$ ); though these patients had higher use of aspirin and clopidogrel in the hospital and during follow-up and higher $\beta$-blockers and statins use during follow-up, they had higher ratios of recurrent angina and composite MACEs during one-year followup (all $P<0.05)$. Logistic regression analyses showed that obesity (OR 1.757, 95\% CI: 1.031 - 2.995), acute coronary syndrome (OR 1.716, 95\% CI: 1.011 - 2.913) and reduced left ventricular ejection fraction (OR 2.539, 95\% CI: 1.180 - 5.463) predict MACEs in a one-year follow-up among patients with PCAD. Conclusions: PCAD patients implanted with DESs have more unstable clinical phenotypes and higher MACEs during a one-year follow-up period, though they were prescribed higher ratios of optimal therapeutic medicine. Further enhanced strategies should be made for secondary prevention.
\end{abstract}

\footnotetext{
"Corresponding author.
}

Keywords: Coronary Artery Disease; Optimal Medicine Therapy; Percutaneous Coronary Intervention; Secondary Prevention; Major Adverse Cardiac Events

\section{INTRODUCTION}

Coronary artery disease (CAD) is one of the major causes of death throughout the world, including China. Although CAD is commonly recognized as a disease associated with age, young patients are also at a risk for coronary atherosclerosis in clinical situations $[1,2]$. People who suffer from CAD during the early years (male $<$ 55 years, female $<65$ years) are considered premature CAD [3]. Patients with premature CAD belong to a particular subgroup deserving much more attention since the impact of premature CAD on individuals, families and society is particularly devastating [4-6].

Recently, significant advances in CAD treatment have taken place, mainly related to the availability and implementation of evidence-based guidelines [7-11] and large scale clinical trials $[12,13]$. Drug-eluting stents (DESs) have also been shown to be associated with a lower restenosis rate in comparison with bare metal stents $[14,15]$. Systematic studies show that secondary prevention programs can improve care, reduce hospital readmission and enhance the quality of life or functional status of patients with CAD undergoing percutaneous coronary intervention (PCI) [7].

Guidelines have been developed and updated to ensure coverage for all eligible patients for optimal treatment and secondary prevention $[8,9]$. However, the use of guidelines, including recommended drugs such as aspirin, $\beta$-blockers, angiotensin converting enzyme inhibitors (ACEIs)/angiotensin II receptor blockers (ARBs) and statins, remains sub-optimal for secondary prevention in most countries [16-21]. Recently, a survey performed including 22 European countries revealed that cardio 
protective medication usage among CAD patients was $78 \%$ to $91 \%$ for $\beta$-blockers, antiplatelets and ACEIs/ ARBs [16]. These data are similar to that obtained in the United States [17]. Available data from India suggest that aspirin is prescribed in $91 \%$ of patients, compared with only $69 \%$ of patients prescribed $\beta$-blockers, $82 \%$ ACEIs/ ARBs and $69 \%$ statins [18]. This status of therapy needs to be increased in order to improve the quality of life, mid- and long-term prognosis of patients at a higher risk.

However, there is only one small sample study [22] which has investigated the use of DESs in patients with premature $\mathrm{CAD}$ in the Chinese population. Our study was designed to assess adherence to secondary preventative medications and provide follow-up outcomes during a one-year follow-up in a larger sample of premature CAD implanted with DESs.

\section{METHODS}

\subsection{Study Population}

From October 2008 to January 2010, 282 patients with confirmed diagnosis of premature CAD (men $<55$ years and women $<65$ years) were enrolled in the present study within our cardiac department. All patients underwent coronary angiography (CAG) for the evaluation of coronary stenosis. Patients with $\geq 50 \%$ stenosis in at least one coronary artery were considered to have CAD. All patients were divided into two groups, coronary stenosis $\geq 70 \%$ in main coronary arteries who underwent PCI and were implanted with DESs (paclitaxel-eluting stent or sirolimus-eluting stent at the discretion of the operator) combined with optimal medical therapy (OMT), and those with coronary stenosis $<70 \%$, without informed consent or with contraindications for aspirin and clopidogrel usage prescribed OMT. Myocardial infarction (MI) was defined according to the World Health Organization criteria and all of the patients with MI also had confirmatory CAG findings. Patients with congenital heart disease, syndrome $\mathrm{X}$, multiple aorto-arteritis, severe liver or kidney disease, or contraindications for heparin usage were excluded from the present study. The investigation conformed with the principles outlined in the Declaration of Helsinki. The study protocol was approved by the Medical Ethics Committee of the Affiliated Zhongda Hospital of Southeast University and written informed consent was obtained from all participants.

\subsection{Determination of Risk Factors and Data Collection}

A questionnaire was completed according to the medical records of all participants. Data were collected including hypertension, type 2 diabetes mellitus (T2DM), family history of CAD, and smoking status. Obesity was de- fined as body mass index (BMI) $\geq 28 \mathrm{~kg} / \mathrm{m}^{2}$ [BMI was calculated as weight in kilograms divided by the square of the height in meters $\left(\mathrm{kg} / \mathrm{m}^{2}\right)$ ] [23]. Two-dimensional echocardiography was used to calculate left ventricular ejection fraction (LVEF) according to the American College of Cardiology and American Heart Association guidelines [24].

Plasma concentrations of total cholesterol, triglyceride, high-density lipoprotein cholesterol, low-density lipoprotein cholesterol, apolipoprotein A1 and apolipoprotein $\mathrm{B}$ were determined using standard methods with a chemical analyzer (Beckman Coulter Synchron Clinical System LX 20, Fullerton, CA, USA). TG was directly measured when the results were $>4.52 \mathrm{mmol} / \mathrm{L}$ (400 $\mathrm{mg} / \mathrm{dL}$ ). Cardiac troponin I (cTnI) was determined using a commercially available kit (Access AccuTnI, Beckman Coulter Inc.).

All patients were followed from discharge to their first cardiac event or end of the study period (January 31, 2011 ) by telephone or a visit at the outpatient clinic. The major follow-up issues included compliance with drug administration for secondary prevention and major adverse cardiac events (MACEs), including stroke, recurrent angina, recurrent MI, and cardiac death.

\subsection{Statistical Analyses}

Statistical analyses were conducted using the SPSS 15.0 software (SPSS, Inc., Chicago, IL). Continuous variables were expressed as mean $\pm \mathrm{SD}$, and a Student's $t$ test or chi-square test was used to analyze differences between the two study groups. Descriptive data were reported as numbers and percentages. Logistic regression analyses were performed to determine factors associated with MACEs during a one-year follow up. Two-tailed P < 0.05 was considered statistically significant.

\section{RESULTS}

\subsection{Baseline Characteristics}

The patient cohort consisted of 282 patients with confirmed premature CAD, including 177 patients implanted with DESs combined with OMT (DESs + OMT) and 105 patients with OMT alone. Patients treated with DESs + OMT had a higher ratio of males, multi-vessel disease, acute coronary syndrome (ACS), higher levels of cTnI, longer hospital stays, higher aspirin and clopidogrel use at discharge compared to OMT alone (all $\mathrm{P}<0.05$ ) (Table 1).

\subsection{Usage of Medicines for Secondary Prevention and Lifestyles during Follow-Up}

Compared to patients treated with OMT, patients treated with DESs + OMT had a higher usage of aspirin and clopidogrel during their time in the hospital, half- and 
Table 1. Baseline characteristics of the study population.

\begin{tabular}{|c|c|c|}
\hline \multirow[b]{2}{*}{ Characteristics } & \multicolumn{2}{|c|}{ PCAD treated PCAD treated with } \\
\hline & $\begin{array}{c}\text { with OMT } \\
(\mathrm{n}=105)\end{array}$ & $\begin{array}{l}\text { DESs + OMT } \\
\quad(\mathrm{n}=177)\end{array}$ \\
\hline Male, $n(\%)$ & $44(41.9)$ & $105(59.3)^{\mathrm{a}}$ \\
\hline \multicolumn{3}{|l|}{ Age, years } \\
\hline Male & $48.84 \pm 4.34$ & $48.97 \pm 5.10$ \\
\hline Female & $56.92 \pm 5.20$ & $56.63 \pm 5.81$ \\
\hline Hypertension, $\mathrm{n}(\%)$ & $79(75.2)$ & $136(76.8)$ \\
\hline Type 2 diabetes mellitus, $\mathrm{n}(\%)$ & $18(17.1)$ & $43(24.3)$ \\
\hline Smoking, $\mathrm{n}(\%)$ & $30(28.6)$ & $60(33.9)$ \\
\hline Obesity, n(\%) & $34(32.4)$ & $59(33.3)$ \\
\hline Drinking, $\mathrm{n}(\%)$ & $13(12.4)$ & $25(14.1)$ \\
\hline Family history of CAD, n(\%) & $20(19.0)$ & $43(24.3)$ \\
\hline $\begin{array}{l}\text { Cardiovascular risk factors per } \\
\text { patient, } n\end{array}$ & $1.84 \pm 1.36$ & $2.10 \pm 1.11$ \\
\hline ACS, $n(\%)$ & $28(26.7)$ & $83(46.9)^{\mathrm{a}}$ \\
\hline Single-vessel disease, $\mathrm{n}(\%)$ & $67(63.8)$ & $62(35.0)^{\mathrm{a}}$ \\
\hline Multi-vessel disease, $\mathrm{n}(\%)$ & $38(36.2)$ & $115(65.0)^{\mathrm{a}}$ \\
\hline cTnI, ng/mL & $0.74 \pm 2.65$ & $4.54 \pm 16.12^{\mathrm{a}}$ \\
\hline $\mathrm{TC}, \mathrm{mmol} / \mathrm{L}$ & $4.61 \pm 1.16$ & $4.63 \pm 1.28$ \\
\hline $\mathrm{TG}, \mathrm{mmol} / \mathrm{L}$ & $1.58 \pm 0.94$ & $1.86 \pm 1.8$ \\
\hline HDL-C, mmol/L & $1.13 \pm 0.57$ & $1.12 \pm 0.29$ \\
\hline LDL-C, mmol/L & $2.92 \pm 1.12$ & $2.84 \pm 0.90$ \\
\hline TC/HDL-C & $4.27 \pm 1.16$ & $4.43 \pm 1.49^{\mathrm{a}}$ \\
\hline LDL-C/HDL-C & $2.58 \pm 0.73$ & $2.82 \pm 1.22^{\mathrm{a}}$ \\
\hline Apo B/Apo A1 & $0.79 \pm 0.29$ & $0.85 \pm 0.34^{\mathrm{a}}$ \\
\hline LVEF, \% & $0.64 \pm 0.09$ & $0.62 \pm 0.10$ \\
\hline Length of hospital stay, days & $6.67 \pm 6.76$ & $8.14 \pm 5.22^{\mathrm{a}}$ \\
\hline $\begin{array}{l}\text { Length of hospital stay after } \\
\text { operation, days }\end{array}$ & $5.55 \pm 5.78$ & $6.98 \pm 4.52^{\mathrm{a}}$ \\
\hline \multicolumn{3}{|l|}{ Medications at discharge } \\
\hline Aspirin, n(\%) & $100(95.2)$ & $176(99.4)^{\mathrm{a}}$ \\
\hline ACEI/ARB, n(\%) & $60(57.1)$ & $105(59.3)$ \\
\hline$\beta$-block, $\mathrm{n}(\%)$ & $66(62.9)$ & 132(74.6) \\
\hline Statins, $\mathrm{n}(\%)$ & $90(85.7)$ & $164(92.7)$ \\
\hline Clopidogrel, $n(\%)$ & $18(17.1)$ & $174(98.3)^{\mathrm{a}}$ \\
\hline
\end{tabular}

${ }^{\mathrm{a}} \mathrm{P}<0.05$, compared with PCAD treated with OMT. Data expressed as the number of individuals (percentage in parentheses) or the mean $\pm \mathrm{SD}$, as appropriate. ACS, acute coronary syndrome; Apo A1, apolipoprotein A1; Apo B, apolipoprotein B; cTnI, cardiac troponin I; DESs, drug-eluting stents; HDL-C, high-density lipoprotein cholesterol; LDL-C, low-density lipoprotein cholesterol; LVEF, left ventricular ejection fraction; OMT, optimal medical therapy; PCAD, premature coronary artery disease; TG, triglyceride; TC, total cholesterol.

one-year follow-up, higher usage of $\beta$-blockers and statins during half- and one-year follow-up (all $\mathrm{P}<0.05$ ). There was a comparable usage of ACEIs/ARBs in the hospital, during the half- and one-year follow-up between the two groups (all $\mathrm{P}>0.05$ ). Smoking and drinking status was also similar in the hospital and during half- and one-year follow-ups between the two groups (all P > 0.05) (Table 2).

\subsection{MACEs during Follow-Up}

Compared to patients treated with OMT alone, patients treated with DESs + OMT had a higher ratio of recurrence of angina and composite MACEs during half- and one-year follow-up (all $\mathrm{P}<0.05$ ) (Table 3).

\subsection{Predictors of MACEs}

Logistic regression analyses showed that obesity, acute coronary syndrome and reduced LVEF $(<50 \%)$ independently predicted MACEs during a one-year follow up among patients with premature CAD (Table 4).

\section{DISCUSSION}

The present study showed that premature CAD patients implanted with DESs were clinically more complicated and unstable. The patients in the DES + OMT group had a higher ratio of multi-vessel disease, ACS and higher levels of cTnI before treatment compared to patients in the OMT group alone. Though these patients had a higher aspirin and clopidogrel use in the hospital and

Table 2. Data on drugs for secondary prevention and lifestyles at baseline and follow-up.

\begin{tabular}{|c|c|c|c|}
\hline & & $\begin{array}{l}\text { PCAD treated with } \\
\text { OMT, } \mathrm{n}(\%) \\
\left(\mathrm{n}^{\dagger}=105 / 105 / 105\right)\end{array}$ & $\begin{array}{l}\text { PCAD treated with } \\
\text { DESs + OMT, } \mathrm{n}(\%) \\
\left(\mathrm{n}^{\dagger}=177 / 177 / 175\right)\end{array}$ \\
\hline \multirow{3}{*}{ Aspirin } & In-hospital & $100(95.2)$ & $176(99.4)^{\mathrm{a}}$ \\
\hline & Half-year & $100(95.2)$ & $177(100.0)^{\mathrm{a}}$ \\
\hline & One-year & $98(93.3)$ & $175(100.0)^{\mathrm{a}}$ \\
\hline \multirow{3}{*}{$\beta$-blockers } & In-hospital & $66(62.9)$ & $132(74.6)$ \\
\hline & Half-year & $62(59.0)$ & $133(75.1)^{\mathrm{a}}$ \\
\hline & One-year & $68(64.8)$ & $139(79.4)^{\mathrm{a}}$ \\
\hline \multirow{3}{*}{$\begin{array}{c}\text { ACEIs/ } \\
\text { ARBs }\end{array}$} & In-hospital & $60(57.1)$ & $105(59.3)$ \\
\hline & Half-year & $62(59.0)$ & $106(59.9)$ \\
\hline & One-year & $67(63.8)$ & $112(64.0)$ \\
\hline \multirow{3}{*}{ Statins } & In-hospital & $90(85.7)$ & $164(92.7)$ \\
\hline & Half-year & $90(84.8)$ & $164(92.7)^{\mathrm{a}}$ \\
\hline & One-year & $92(87.6)$ & $164(93.7)^{\mathrm{a}}$ \\
\hline \multirow{3}{*}{ Clopidogrel } & In-hospital & $18(17.1)$ & $174(98.3)^{\mathrm{a}}$ \\
\hline & Half-year & $20(19.0)$ & $174(98.3)^{\mathrm{a}}$ \\
\hline & One-year & $22(21.0)^{\mathrm{a}}$ & $173(98.9)^{\mathrm{a}}$ \\
\hline \multirow{3}{*}{ Smoking } & In-hospital & $30(28.6)$ & $60(33.9)$ \\
\hline & Half-year & $8(7.6)$ & $18(10.2)$ \\
\hline & One-year & $7(6.7)$ & $7(4.0)$ \\
\hline \multirow{3}{*}{ Drinking } & In-hospital & $13(12.4)$ & $25(14.1)$ \\
\hline & Half-year & $4(3.8)$ & $10(5.6)$ \\
\hline & One-year & $6(5.7)$ & $7(4.0)$ \\
\hline
\end{tabular}

${ }^{\mathrm{a}} \mathrm{P}<0.05$, compared with PCAD treated with OMT. Data expressed as the number of individuals (percentage in parentheses) or the mean $\pm \mathrm{SD}$, as appropriate. 'Represents the available number of patients in hospital, halfyear and one-year follow-up. ACEI, angiotensin converting enzyme inhibittor; ARB, angiotensin II receptor blocker; DESs, drug-eluting stents; OMT, optimal medicine therapy; PCAD, premature coronary artery disease. 
Table 3. Follow-up results of MACEs.

\begin{tabular}{cccc}
\hline \multirow{2}{*}{ Stroke } & Half-year & $\begin{array}{c}\text { PCAD treated with } \\
\text { OMT, n(\%) } \\
\left(\mathrm{n}^{\dagger}=105 / 105\right)\end{array}$ & $\begin{array}{c}\text { PCAD treated with } \\
\text { DESs + OMT, n(\%) } \\
\left(\mathrm{n}^{\dagger}=177 / 175\right)\end{array}$ \\
& One-year & $4(3.8)$ & $3(1.7)$ \\
\multirow{2}{*}{ Recurrent angina } & Half-year & $15(14.3)$ & $3(1.7)$ \\
& One-year & $18(17.1)$ & $47(26.6)^{\mathrm{a}}$ \\
\multirow{2}{*}{ Recurrent MI } & Half-year & $1(1.0)$ & $61(34.5)^{\mathrm{a}}$ \\
\multirow{2}{*}{ Cardiac death } & One-year & $1(1.0)$ & $1(0.6)$ \\
Composite & Half-year & $0(0.0)$ & $3(1.7)$ \\
MACEs & One-year & $0(0.0)$ & $3(1.1)$ \\
& Half-year & $18(17.1)$ & $53(29.9)^{\mathrm{a}}$ \\
\hline
\end{tabular}

${ }^{\mathrm{a} P}<0.05$, compared with PCAD treated with OMT. "Represents the available number of patients in half-year and one-year follow-up. DESs, drugeluting stents; MACEs, major adverse cardiac events; MI, myocardial infarction; PCAD, premature coronary artery disease; OMT, optimal medicine therapy.

Table 4. Logistic regression analysis on composite MACEs and predictors during one-year follow up.

\begin{tabular}{ccccc}
\hline & B value & EXP $(\mathrm{B})$ & $95 \%$ CI & P value \\
\hline Obesity & 0.564 & 1.757 & $1.031-2.995$ & 0.038 \\
ACS & 0.540 & 1.716 & $1.011-2.913$ & 0.045 \\
Decreased LVEF & 0.932 & 2.539 & $1.180-5.463$ & 0.017 \\
Therapy with DESs & 0.554 & 1.740 & $0.994-5.463$ & 0.052 \\
\hline
\end{tabular}

Logit $\mathrm{P}=-1.566+0.564$ Obesity +0.540 ACS +0.932 LVEF +0.554 Therapy with DESs. ACS, acute coronary syndrome; DESs, drug-eluting stents; LVEF, left ventricular ejection fraction; MACEs, major adverse cardiac events.

during follow-up and higher use of $\beta$-blockers and statins during follow-up, they still had longer hospital stays and higher ratios of composite MACEs during follow-up than those treated with optimal medical therapy alone. So it is reasonable that the worse outcome of patients treated with DES is due to more severe diseases at the time of diagnosis. Obesity, ACS and reduced LVEF independently predicted MACEs during a one-year follow up.

Recently, the benefits of OMT on the reduction of MACEs have been demonstrated in clinical trials $[10,12$, 13]. Several studies of premature CAD focused on the association with traditional risk factors including smoking, dyslipidemia, hypertension, diabetes, family history of CAD and male sex [5,6], without determining DESs and the updated guidelines for secondary prevention.

In our study, patients implanted with DESs were more likely to be male who had a higher prevalence of family history of CAD, multi-vessel disease and higher levels of cTnI, suggesting that these patients were clinically more complicated and had unstable clinical phenotypes. Compared to those treated with OMT alone, even though these patients had higher aspirin and clopidogrel use in the hospital during follow-up and higher $\beta$-blocker and statin use during follow-up, they still had longer hospital stays, higher ratios of composite MACEs during follow-up, suggesting that they had poor short- and midterm prognoses. More effective measures should be taken to control modifiable risk factors in order to increase the ratio of optimal medication use and life-style interventions. Patients at a risk for heart failure with a LVEF $\leq 40 \%$ can make changes in their lifestyle to achieve similar medical and psychosocial benefits to patients with normal LVEF [25]. Also, a recent study showed that CAD patients with asymptomatic reduced LVEF can safely delay revascularization using lifestyle modification without increased risks for cardiac events or overt heart failure for three years [26].

Guidelines based on evidence from randomized controlled trails recommend that aspirin, $\beta$-blockers, ACEIs and statins be used in all patients with CAD. It has been the consensus that, if used optimally, these agents can reduce long-term risks of cardiovascular events and mortality. However, there remains a low use of secondary preventative therapies throughout the world, including Europe [16], the United States [17,21], India [18] and Israel [19]. Recently, one study conducted in China showed that the use of aspirin, $\beta$-blockers and statins was $91.4 \%, 66.5 \%$ and $67.4 \%$ respectively among ACS patients with heart failure [27]. Compared with the data described above, our study revealed a remarkably higher ratio of drug administration in patients with premature CAD in the hospital and during the follow-up, with aspirin usage at $95.2 \%-100 \%, \beta$-blockers $59.0 \%-79.40 \%$, and statins $84.8 \%$ - $93.7 \%$ respectively. This may represent a more appropriate use of evidence-based therapies at tertiary care clinics which might differ from that in primary and secondary care units.

Some strengths and limitations of this study should be mentioned. Firstly, this was not a multi-center study, so it is unlikely that the subjects enrolled in our study adequately represented population characteristics included in other studies [16-21,28]. However, our study sample was routinely seen by practitioners in the real world and may well represent a few of the patients who came for medical attention due to symptomatic CAD [4]. Secondly, since we did not mention the reasons why patients were not taking preventative drugs, it was not possible to assess the true status of contraindications or intolerance of certain drugs among these patients. However, these patients underwent regular visits to our outpatient service and withdrew from medication usage were less likely to influence the comparison between the two groups. Finally, our study only reported the mid-term outcomes of this study sample; long-term follow-up was warranted to acquire convincing data in this specific field.

In summary, the present study showed that premature CAD patients implanted with DESs are clinically unsta- 
ble without full usage of secondary preventive medications, and have worse one-year outcomes. How to increase medication compliance, strengthen life-style perfection and make best predictions between revascularization and optimal medicine therapy to improve the quality of patient life and long-term prognosis remains an important issue [29,30]. Firstly, better awareness and implementation of guideline-recommended therapies must be raised among physicians to increase their implementation and younger CAD patients implanted DESs must be motivated to adopt optimal preventative measures by their physicians. Secondly, regular nurse-led interventions, telephone monitoring and internet-oriented selfeducation should be strengthened to increase patients' life-style interventions and drug compliance [25,26,31, 32].

\section{REFERENCES}

[1] Akosah, K.O., Gower, E., Groon, L., Rooney, B.L. and Schaper, A. (2000) Mild hypercholesterolemia and premature heart disease: Do the national criteria underestimate disease risk? Journal of the American College of Cardiology, 35, 1178-1184. doi:10.1016/S0735-1097(00)00556-8

[2] Gurevitz, O., Jonas, M., Boyko, V., Rabinowitz, B. and Reicher-Reiss, H. (2000) Clinical profile and long-term prognosis of women/or $=50$ years of age referred for coronary angiography for evaluation of chest pain. American Journal of Cardiology, 85, 806-809. doi:10.1016/S0002-9149(99)00871-1

[3] Expert Panel on Detection, Evaluation, and Treatment of High Blood Cholesterol in Adults (2001) Executive summary of the third report of the national cholesterol education program expert panel on detection, evaluation, and treatment of high blood cholesterol in adults (adult treatment panel III). JAMA, 285, 2486-2497. doi:10.1001/jama.285.19.2486

[4] Klein, L.W. and Nathan, S. (2003) Coronary artery disease in young adults. Journal of the American College of Cardiology, 41, 529-531. doi:10.1016/S0735-1097(02)02861-9

[5] Cole, J.H., Miller 3rd, J.I., Sperling, L.S. and Weintraub, W.S. (2003) Long-term follow-up of coronary artery disease presenting in young adults. Journal of the American College of Cardiology, 41, 521-528. doi:10.1016/S0735-1097(02)02862-0

[6] Cole, J.H. and Sperling, L.S. (2004) Premature coronary artery disease: Clinical risk factors and prognosis. Current Atherosclerosis Reports, 6, 121-125. doi:10.1007/s11883-004-0100-Z

[7] Khunti, K., Stone, M., Paul, S., Baines, J., Gisborne, L., Farooqi, A., Luan, X. and Squire, I. (2007) Disease management programme for secondary prevention of coronary heart disease and heart failure in primary care: A cluster randomised controlled trial. Heart, 93, 1398-1405. doi:10.1136/hrt.2006.106955

[8] AHA, ACC, National Heart, Lung and Blood Institute,
Smith Jr, S.C., Allen, J., Blair, S.N., Bonow, R.O., Brass, L.M., Fonarow, G.C., Grundy, S.M., Hiratzka, L., Jones, D., Krumholz, H.M., Mosca, L., Pearson, T., Pfeffer, M.A. and Taubert, K.A. (2006) AHA/ACC guidelines for secondary prevention for patients with coronary and other atherosclerotic vascular disease: 2006 update endorsed by the National Heart, Lung and Blood Institute. Journal of the American College of Cardiology, 47, 2130-2139.

[9] Graham, I., Atar, D., Borch-Johnsen, K., Boysen, G., Burell, G., Cifkova, R., Dallongeville, J., De Backer, G., Ebrahim, S., Gjelsvik, B., Herrmann-Lingen, C., Hoes, A., Humphries, S., Knapton, M., Perk, J., Priori, S.G., Pyorala, K., Reiner, Z., Ruilope, L., Sans-Menendez, S., Op Reimer, W.S., Weissberg, P., Wood, D., Yarnell, J., Zamorano, J.L. and ESC Committee for Practice Guidelines (2007) European guidelines on cardiovascular disease prevention in clinical practice: Executive summary. Atherosclerosis, 194, 1-45.

[10] Pasternak, R.C., Smith Jr., S.C., Bairey-Merz, C.N., Grundy, S.M., Cleeman, J.I., Lenfant, C., American College of Cardiology, American Heart Association, National Heart, Lung and Blood Institute (2002) ACC/AHA/ NHLBI clinical advisory on the use and safety of statins. Journal of the American College of Cardiology, 40, 567572. doi:10.1016/S0735-1097(02)02030-2

[11] American College of Cardiology and American Heart Association Task Force on Practice Guidelines (2008) 2007 focused update of the ACC/AHA/SCAI 2005 guideline update for percutaneous coronary intervention. A report of the American College of Cardiology/American Heart Association Task Force on Practice Guidelines. $\mathrm{Ca}$ theterization and Cardiovascular Interventions, 71, E1E40. doi:10.1002/ccd.21475

[12] Hjalmarson, A., Goldstein, S., Fagerberg, B., Wedel, H., Waagstein, F., Kjekshus, J., Wikstrand, J., El Allaf, D., Vítovec, J., Aldershvile, J., Halinen, M., Dietz, R., Neuhaus, K.L., Jánosi, A., Thorgeirsson, G., Dunselman, P.H., Gullestad, L., Kuch, J., Herlitz, J., Rickenbacher, P., Ball, S., Gottlieb, S. and Deedwania, P. (2000) Effects of controlled-release metoprolol on total mortality, hospitalizations, and well-being in patients with heart failure: The metoprolol $\mathrm{CR} / \mathrm{XL}$ randomized intervention trial in congestive heart failure (MERIT-HF). JAMA, 283, 12951302. doi:10.1001/jama.283.10.1295

[13] Yusuf, S., Sleight, P., Pogue, J., Bosch, J., Davies, R., Dagenais, G. and The Heart Outcomes Prevention Evaluation Study Investigators (2000) Effects of an angiotensin-converting enzyme inhibitor, ramipril, on cardiovascular events in high-risk patients. The New England Journal of Medicine, 342, 145-153. doi:10.1056/NEJM200001203420301

[14] Moses, J.W., Leon, M.B., Popma, J.J., Fitzgerald, P.J., Holmes, D.R., O’Shaughnessy, C., Caputo, R.P., Kereiakes, D.J., Williams, D.O., Teirstein, P.S., Jaeger, J.L., Kuntz, R.E. and SIRIUS Investigators (2003) Sirolimuseluting stents versus standard stents in patients with stenosis in a native coronary artery. The New England Journal of Medicine, 349, 1315-1323. doi:10.1056/NEJMoa035071

[15] Stone, G.W., Ellis, S.G., Cox, D.A., Hermiller, J., 
O’Shaughnessy, C., Mann, J.T., Turco, M., Caputo, R., Bergin, P., Greenberg, J., Popma, J.J., Russell, M.E. and TAXUS-IV Investigators (2004) A polymer-based, paclitaxel-eluting stent in patients with coronary artery disease. The New England Journal of Medicine, 350, 221-231. doi:10.1056/NEJMoa032441

[16] Kotseva, K., Wood, D., De Backer, G., De Bacquer, D., Pyörälä, K., Keil, U. and EUROASPIRE Study Group (2009) EUROASPIRE III: A survey on the lifestyle, risk factors and use of cardioprotective drug therapies in coronary patients from 22 European countries. European Journal of Cardiovascular Prevention \& Rehabilitation, 16, 121-137. doi:10.1097/HJR.0b013e3283294b1d

[17] Lewis, S.J., Robinson, J.G., Fox, K.M., Grandy, S. and SHIELD Study Group (2010) Underutilisation of cardiovascular medications among at-risk individuals. International Journal of Clinical Practice, 64, 604-610. doi:10.1111/j.1742-1241.2009.02258.x

[18] Sharma, K.K., Gupta, R., Agrawal, A., Roy, S., Kasliwal, A., Bana, A., Tongia, R.K. and Deedwania, P.C. (2009) Low use of statins and other coronary secondary prevention therapies in primary and secondary care in India. Vascular Health and Risk Management, 5, 1007-1014.

[19] Moriel, M., Tzivoni, D., Behar, S., Zahger, D., Hod, H., Hasdai, D., Sandach, A. and Gottlieb, S. (2008) Contemporary treatment and adherence to guidelines in women and men with acute coronary syndromes. International Journal of Cardiology, 131, 97-104. doi:10.1016/j.ijcard.2007.09.005

[20] Javed, U., Deedwania, P.C., Bhatt, D.L., Cannon, C.P., Dai, D., Hernandez, A.F., Peterson, E.D. and Fonarow, G.C. (2010) Use of intensive lipid-lowering therapy in patients hospitalized with acute coronary syndrome: An analysis of 65,396 hospitalizations from 344 hospitals participating in Get With The Guidelines (GWTG). American Heart Journal, 160, 1130-1136.

doi:10.1016/j.ahj.2010.08.041

[21] Arnold, S.V., Spertus, J.A., Tang, F., Krumholz, H.M., Borden, W.B., Farmer, S.A., Ting, H.H. and Chan, P.S. (2011) Statin use in outpatients with obstructive coronary artery disease. Circulation, 124, 2405-2410. doi:10.1161/CIRCULATIONAHA.111.038265

[22] Wang, M.H., Lee, W.L., Wang, K.Y., Hsieh, Y.C., Liu, T.J., Lin, I.H., Lin, W.W., Ting, C.T. and Liang, K.W. (2008) Short-term follow-up results of drug-eluting stenting in premature coronary artery disease patients with multiple atherosclerotic risk factors. Journal of the Chinese Medical Association, 71, 342-346. doi:10.1016/S1726-4901(08)70136-9

[23] Zhou, B. (2002) Predictive values of body mass index and waist circumference to risk factors of related diseases in Chinese adult population. Chinese Journal of Epidemiology, 23, 5-10.

[24] Cheitlin, M.D., Armstrong, W.F., Aurigemma, G.P., Beller, G.A., Bierman, F.Z., Davis, J.L., Douglas, P.S., Faxon, D.P., Gillam, L.D., Kimball, T.R., Kussmaul, W.G., Pearlman, A.S., Philbrick, J.T., Rakowski, H., Thys, D.M., Antman, E.M., Smith Jr., S.C., Alpert, J.S., Gregoratos, G., Anderson, J.L., Hiratzka, L.F., Hunt, S.A.,
Fuster, V., Jacobs, A.K., Gibbons, R.J., Russell, R.O., American College of Cardiology, American Heart Association and American Society of Echocardiography (2003) ACC/AHA/ASE 2003 guideline update for the clinical application of echocardiography: Summary article: A report of the American College of Cardiology/American Heart Association Task Force on practice guidelines (ACC/AHA/ASE Committee to update the 1997 guidelines for the clinical application of echocardiography). Circulation, 108, 1146-1162.

doi:10.1161/01.CIR.0000073597.57414.A9

[25] Pischke, C.R., Weidner, G., Elliott-Eller, M. and Ornish, D. (2007) Lifestyle changes and clinical profile in coronary heart disease patients with an ejection fraction of $\leq 40 \%$ or $>40 \%$ in the Multicenter Lifestyle Demonstration Project. European Journal of Heart Failure, 9, 928934. doi:10.1016/j.ejheart.2007.05.009

[26] Pischke, C.R., Elliott-Eller, M., Li, M., Mendell, N., Ornish, D. and Weidner, G. (2010) Clinical events in coronary heart disease patients with an ejection fraction of $40 \%$ or less: 3-year follow-up results. Journal of Cardiovascular Nursing, 25, E8-E15.

[27] Wang, N., Zhao, D., Liu, J., Liu, J., Yu, C.M., Wang, W., Sun, J., Li, Y. and Du, F. on Behalf of the BRIG Project (2011) Impact of heart failure on in-hospital outcomes of acute coronary syndrome patients in China-Results from the bridging the gap on CHD secondary prevention in China (BRIG) project. International Journal of Cardi$o l o g y$, in Press.

[28] Meliga, E., De Benedictis, M., Gagnor, A., Belli, R., Scrocca, I., Lombardi, P., Conrotto, F., Aranzulla, T., Varbella, F. and Conte, M.R. (2012) Long-term outcomes of percutaneous coronary interventions with stent implantation in patients $\leq 40$ years old. American Journal of Cardiology, 109, 1717-1721. doi:10.1016/j.amjcard.2012.01.400

[29] Boden, W.E., O'Rourke, R.A., Teo, K.K., Hartigan, P.M., Maron, D.J., Kostuk, W.J., Knudtson, M., Dada, M., Casperson, P., Harris, C.L., Chaitman, B.R., Shaw, L., Gosselin, G., Nawaz, S., Title, L.M., Gau, G., Blaustein, A.S., Booth, D.C., Bates, E.R., Spertus, J.A., Berman, D.S., Mancini, G.B., Weintraub, W.S. and COURAGE Trial Research Group (2007) Optimal medical therapy with or without PCI for stable coronary disease. The New England Journal of Medicine, 356, 1503-1516. doi:10.1056/NEJMoa070829

[30] Stergiopoulos, K. and Brown, D.L. (2012) Initial coronary stent implantation with medical therapy vs medical therapy alone for stable coronary artery disease: Metaanalysis of randomized controlled trials. Archives of Internal Medicine, 172, 312-319. doi:10.1001/archinternmed.2011.1484

[31] Allen, J.K. and Dennison, C.R. (2010) Randomized trials of nursing interventions for secondary prevention in patients with coronary artery disease and heart failure: Systematic review. Journal of Cardiovascular Nursing, 25, 207-220.

[32] Soran, O.Z., Feldman, A.M., Piña, I.L., Lamas, G.A., Kelsey, S.F., Selzer, F., Pilotte, J. and Lave, J.R. (2010) Cost of medical services in older patients with heart fail- 
ure: Those receiving enhanced monitoring using a computer-based telephonic monitoring system compared with those in usual care: The heart failure home care trial.
Journal of Cardiac Failure, 16, 859-866. doi:10.1016/j.cardfail.2010.05.028

\section{LIST OF ABBREVIATIONS}

ACS: acute coronary syndrome

ACEIs: angiotensin converting enzyme inhibitors

ARBs: angiotensin II receptor blockers

BMI: body mass index

cTnI: cardiac troponin I

CAG: coronary angiography

CAD: coronary artery disease

DESs: drug-eluting stents

LVEF: left ventricular ejection fraction

MACEs: major adverse cardiac events

MI: myocardial infarction

OMT: optimal medicine therapy

PCI: percutaneous coronary intervention

T2DM: type 2 diabetes mellitus 